\title{
An Assessment of the Impact of Government Intervention Projects on Poverty Alleviation/Reduction in Ekiti State, Nigeria
}

\author{
Zacheus. O. Opafunso \\ Dean, School of Management Technology, Federal \\ University of Technology, Akure, Nigeria. \\ Email: zopafunso@yahoo.com \\ Omonigho. T. Okhankhuele \\ Department of Project Management Technology, Federal \\ University of Technology, Akure, Nigeria \\ Email:omotonia2013@gmail.com
}

Doi:10.5901/mjss.2014.v5n4p273

\begin{abstract}
This study assessed the impact of Ekiti State Government's intervention projects on poverty alleviation/reduction in Ekiti State, Nigeria, from 2007-2011. The paper identified some intervention projects/programmes executed in six Local Government Areas in the three Senatorial Districts selected for this study, identified the providers of these projects, and assessed the extent to which the projects impacted on poverty alleviation of the people. The study attempted finding answers to research questions by using survey design and judgemental sampling technique to collect data from 630 respondents with the aid of a 25-item structured questionnaire and personal interview. The respondents comprised of civil servants, farmers, and traders/artisans within the communities. Data for this study were analysed using descriptive statistics and chi-square (X2) was used to test the hypothesis posed for the research at $5 \%$ significant level. The findings revealed that developmental projects were implemented by the State, local government and international/non-governmental agencies within the study area during the study period. Also there was an impact of government's intervention projects on poverty alleviation in Ekiti State within the study period but, the impact was insignificant. The study recommended proper coordination of efforts of all parties towards the poverty alleviation intervention programmes in Ekiti State in order to avoid duplication of efforts, implementation of a well-planned and concerted policy framework, projects/programmes, and provision of an adequate budget towards poverty alleviation/reduction in Ekiti State by the Federal and Ekiti State governments, and the involvement of the community members in the conceptualization, and implementation of projects.
\end{abstract}

Keywords: Poverty, Poverty Alleviation/Reduction, Intervention Projects/Programmes, Life uplift

\section{Introduction}

The problem of how to reduce poverty has remained a dilemma to leaders all over the globe and the international community, especially in Sub-Saharan Africa where poverty abounds. A report by the World Bank (1996) reveals that about 43 percent of the population was living below poverty line of N395 a year in 1985, and this number declined to 34 percent by 1992. Also the level of poverty increased from 1992-1995 due to unpleasant policy changes in the economy. In order to help fight poverty, the United Nations declared 1996 as the "International year for the eradication of poverty" and October $17^{\text {th }}$ each year as the "International Day for the eradication of poverty".

To address this precarious situation, the International Community under the patronage of the United Nations in the year 2000, agreed on the Millennium Development Goals (MDGs), to wage war against poverty all over the globe. MDGs which was formulated in the year 2000 when a total of 192 members of the United Nations signed the Millennium Declaration at Millennium summit had eight developmental goals to be achieved between 2000 and 2015. These eight (8) goals include to: Eradicate extreme poverty and hunger, Universal education, Gender equity, child health, Material health, Combat HIVIAIDS and other diseases, Environmental sustainability, Global partnership (Olise, 2010). One of the sub-components of the first goal is the need to reduce the proportion of people living on less than one US dollar per day and to reduce by half the proportion of people who suffer from hunger. This translates to reducing by half the number of people living on N126.00 per day or less than N3,780.00 per month by the year 2015 (Olatunji, 2008). To associate with 
MDGs and integrate them into the development agenda of developing countries like Nigeria, most governments of developing countries came out with diverse development programmes to uplift the quality of life of her citizens. Therefore, "as part of his development agenda for Nigeria, President Musa Yar'Adua, declared a 7-point agenda for Nigeria upon assumption of office on May 29th 2009 . These 7-point agenda include: Critical infrastructure; The Niger Delta; Food Security; Human Capital Development; Land Tenure Changes and Home Ownership; National Security Intelligence and wealth Creation" (Olise, 2010).

Successive governments in Ekiti State since its creation from the old Ondo State in 1996 have carried out one strategy or another (as complement to that of the Federal government) aimed at alleviating/reducing the suffering of the people and put smiles on the faces of its indigenes. Some of these developmental efforts were directed towards the following areas: Industrial development/expansion of Small and Medium Scale Enterprises (SME's); Infrastructural development/construction and or rehabilitation of rural and urban roads; Environmental development and improved sanitation/waste management; Provision of social service/facilities such as water/electricity supply, health care delivery services and better education facilities, Women/gender development and youth empowerment; and Administration and good governance. Also, Ekiti State Community Based Poverty Reduction managed by Ekiti State Poverty Reduction Agency (EKPRA), Local Government Areas/Community Participatory Rural Development Programme (facilitated by United Nations International Children Emergency Fund (UNICEF) under the Community Participatory Rural Appraisal (PRA), Rural roads/bridges development programme facilitated by Department For International Development (DFID), and Community Water/Health intervention programmes facilitated by Federal Government of Nigeria/UNICEF/MDGs. Notwithstanding this, there still exist the incidence of mass poverty in Ekiti state. The issue of poverty reduction has also been given significant attention by successive governments in Nigeria. Many plans, policies, programmes and strategies have been carried out by past governments in Nigeria to alleviate poverty especially in the rural areas where poverty abounds, to no avail. Adebayo (2009) alleged that various policies, programmes and projects were carried out by various governments so as to directly reduce/eradicate poverty or indirectly affect it. He was of the opinion that policies formulated can be divided into two - general development polices with some poverty bias and policies that are specifically aimed at poverty reduction.

Review of past literature on poverty shows that there is no standard concept of poverty because of its dynamic properties. In the words of Aboyade (1975), "Poverty, like an elephant, is more easily recognized than defined". Sen (1985) defined poverty as "lack of capability to function in a given society". Elumilade et al (2006) view "Poverty is an economic condition in which a section of the society or a specific group of people lack sufficient income to obtain a minimum level of health services, food, housing, clothing, and education which are generally recognized as necessary to assume adequate standard of living". They further stated that about $46.5 \%$ of African population live below one dollar (\$1) a day. Poverty is associated with a feeling of dependency, hopelessness, fear for future, lack of integrity, hunger, lack of descent shelter, health care, education, and infrastructural amenities, oppression, joblessness, etc. World Bank (2001), summarized the various dimensions as "a lack of opportunity, lack of empowerment and a lack of security". Ogwumike (2002) declared that, the poor, live in a state characterized by inadequate resources (material and human) and high consumption levels. Thirlwall (2003) stated, "in poverty, there is a feeling of powerlessness, vulnerability and fear because the poor is not free, he is exposed to greater risks and living on the margin of subsistence. This definition expresses poverty as state of lack, want or need for the survival of a person or persons in the society.

\section{Statement of the Problem}

Despite all the plans, policies, programmes and strategies carried out by past governments (Federal, State, Local Government), and international/non-governmental agencies in Nigeria, to alleviate poverty especially in the rural areas, majority of Nigerians, Ekiti State indigenes inclusive, especially those who live in the rural areas, still wallow in poverty. Why? While some of the past studies concluded that the impact of the programmes and projects was significant, some other studies concluded that the impact was insignificant. Also that the failure of the numerous projects/programmes was due to insincerity of purpose by the government and its officials' corruption, embezzlement of the resources meant for the implementation of poverty alleviating/reducing projects/programmes, lack of transparency and lack of coordination of the efforts of all the parties that contributed to poverty alleviating/reducing projects/programmes in Nigeria. What were the poverty alleviation intervention projects/programmes executed in six Local Government Areas in the three Senatorial Districts selected for this study within the study period, who were the providers of these projects, and to what extent did the government's intervention projects impact on poverty alleviation of the people of Ekiti state from 2007-2011? The researcher intends to find answers to these questions, by carrying out study on six Local Government Areas in three 
Senatorial Districts in Ekiti State, Nigeria. The findings revealed that some developmental projects were implemented by the State, local government and international/non-governmental agencies in Ekiti State during the study period, the impact of the projects was positive but of little significant on poverty alleviation of the people of Ekiti State.

The broad objective of this study is to assess the impact of government's intervention projects on poverty alleviation/reduction in Ekiti State, Nigeria, from 2007-2011, and the specific objectives are to: identify some core intervention projects/programmes executed in six Local Government Areas in the three Senatorial Districts in Ekiti State, during the study period, identify the providers of these projects, and assess the extent to which the projects impacted on poverty alleviation of the people of Ekiti State, Nigeria.

\section{Previous Research}

\subsection{Some Past Nigerian Government's Poverty Alleviation and Developmental Policies and Strategies}

The Nigerian Government had in the past carried out a number of programmes to alleviate poverty and develop the country. Some of these programmes include:

Table 1: Poverty Reduction Programmes in Nigeria from 1986 to 2005

\begin{tabular}{|c|c|c|c|}
\hline Programmes & \begin{tabular}{c|} 
Year \\
Established
\end{tabular} & Target Group & Name of Intervention \\
\hline $\begin{array}{l}\text { Directorate for Food Road \& Rural } \\
\text { Infrastructures (DFRRI) }\end{array}$ & 1986 & Rural Areas & $\begin{array}{c}\text { Feeder roads, rural water supply and rural } \\
\text { electrifications }\end{array}$ \\
\hline $\begin{array}{l}\text { National Directorate of Employment } \\
\text { (NDE) }\end{array}$ & 1986 & Unemployed Youths & Training Finance and guidance \\
\hline Better Life Programme (BLP) & 1987 & Rural Women & $\begin{array}{l}\text { Self-help and rural development programmes, skill } \\
\text { acquisition and health care. }\end{array}$ \\
\hline People's Bank of Nigeria (PBN) & 1989 & $\begin{array}{l}\text { Underprivileged in rural and urban } \\
\text { areas }\end{array}$ & Encouraging savings and credit facilities \\
\hline Community Banks (CBs) & 1990 & $\begin{array}{l}\text { Rural residents micro enterprise in } \\
\text { urban areas }\end{array}$ & Banking facilities \\
\hline Family Support Programme (FSP) & 1994 & Families in rural areas & $\begin{array}{l}\text { Health care delivery child welfare, youth } \\
\text { development, etc }\end{array}$ \\
\hline $\begin{array}{l}\text { Family Economic Advancement } \\
\text { Programme (FEAP) }\end{array}$ & 1997 & Rural Areas & $\begin{array}{l}\text { Credit facilities to support the establishment of } \\
\text { cottage industries }\end{array}$ \\
\hline Poverty Alleviation Programme (PAP) & 1999 & Poor People & Job creation \\
\hline $\begin{array}{l}\text { National Poverty Eradication Programme } \\
\text { (NAPEP) }\end{array}$ & 2001 & $\begin{array}{l}\text { Poor people and unemployed in rural } \\
\text { and urban areas }\end{array}$ & Job creation and credit facilities to the poor \\
\hline $\begin{array}{l}\text { Women and Youth Employment Scheme } \\
\text { (W-YES) }\end{array}$ & 2005 & Women and Unemployed Youths & To create sustainable employment \\
\hline Micro Credit Scheme & 2005 & $\begin{array}{l}\text { Cooperative Banks and Small \& } \\
\text { Medium Enterprises }\end{array}$ & To give loans \\
\hline
\end{tabular}

Source: Ogwumike, (2002 and Obayelu, (2005)

\subsection{An Evaluation of Poverty Alleviation Programmes/Policies and Poverty Reduction Strategies in Nigeria}

Several strategies to the alleviation of poverty in Nigeria especially in the rural areas where poverty abounds have been carried out with varying degree of successes and failures. Several writers including: Olujimi (2001), Kadiri (1998), Nwabueze (2004), Nwanna (2004), Nwakeze (2004), Fashola (2004) among others, have expatiated on these efforts and there conclusions pointed to the same direction that rural development policies as expressed in the First and Second National Development Plans (1962-1968, and 1970-1974) were a follow-up from the colonial period when rural development was likened with agricultural development with focus on production for export. In the Second Development Plan (1970-1974), the strategy for rural development was still based on agriculture. However, in the Third National Development Plan (1975-1980) some rural developmental objectives were included such as: to increase rural income and production, to expand the rural economy, and improve the quality of life of the rural inhabitants by providing them with basic socio-economic amenities such as, electricity, pipe born water, motor able roads, health and educational facilities, among others.

Farm Settlement Scheme was introduced to alleviate unemployment problem for school leavers, Community 
Development Programme was introduced with the intent to elevate the quality of life of the rural inhabitants, The National Accelerated Food Production Programme (NAFPP) (1974) was envisaged to deliver better-quality and high yield varieties of farm inputs like High Yield Variety (HYV) fertilizers, pesticides, credit and farmer management to farmers, to guarantee the adequacy of food supply for the growing population. Some progress was made here in respect to adoptive research. The River Basin Development Authority (1976) was established to make available adequate water for agricultural production, Operation Feed the Nation Programme (OFN) (1976) was established to mobilize the Nigerian population into the production of adequate food for its people by the use of better agricultural practices. The Green Revolution Programme (1980) accentuated the objectives of OFN. The Agriculture Development programme (ADP) was established to increase food production, production of industrial raw materials, and increase the real income of farmers. This programme made it possible for imported new agricultural technology to be introduced and used in Nigeria, but its improvement and change on Nigerian farmers' agricultural practices was insignificant. The Directorate of Foods, Roads and Rural Infrastructure (DFRRI) (1986) was established to make available rural infrastructures, improve agricultural and industrial production, and promote pertinent technologies that would help alleviate the quality of life of the rural inhabitants. The Structural Adjustment Programme (SAP) (1986), "turned out in Nigeria to be a remedy not for economic revival but for decline and attainment of equilibrium at a lower level" (Ishola, 2004). He further stated that, the economic situation has deteriorated to such an appalling level to the extent that manufacturing companies in Nigeria have converted factories to warehouses for refilling and repackaging finished imported goods, signifying a near breakdown of the manufacturing sector in Nigeria. ljaiya (1998) opined that since the global economic crisis of 1980s, and the introduction of SAP in 1986, Nigeria has been beset with some severe economic problems which has aided in the increase in poverty level of its people, thus causing a lot of hardships to the people.

Also, more poverty reduction programmes were introduced by Nigerian government from 1993 to 1998. They include: the National Directorate for Employment (NDE), Better Life Programme (BLP), People's Bank of Nigeria (PBN), Community Banks (CB), Family Support Programme (FSP) and the Family Economic Advancement Programme (FEAP). In 1994, the Government set up abroad-based Poverty Alleviation Programme Development Committee (PAPDC) with a primary objective to advise the government on the design, coordinate and implement poverty alleviation programmes. Its work contributed immensely to the emergence of a new approach to the designing and organization of poverty alleviation programmes. In 1996, the Community Action Programme for Poverty Alleviation (CAPPA) was introduced. This was a community based approach which adopted a combination of social funds and social action strategy. It was intended to ensure that the poor partake in the designing, formulation, implementation and management of poverty alleviation projects that affect them. Various agencies (Governments, Donors and NGOs) involved in poverty alleviation projects in the country have embraced the CAPPA's strategy. Also introduced was Integrated Rural Development. This Approach was intended to transform the rural areas holistically - socio-culturally, economically, politically, physically, technologically, etc. "It is a holistic approach which involves the development of all areas of the rural sector such as health, education, agriculture, rural electrification, housing, water resources and transportation" (Akande, 1986). In spite of all these programmes, the rural areas in Nigeria are still in a pitiable state of poverty, lack and hardship. Nwabueze (2004), Nwanna (2004) and some other authors relate the failure of these programmes to: lack of genuine political support, lack of continuity in programme implementation resulting from instability in government, poor conceptualization of the problem of poverty in Nigeria, lack of political willpower, non-involvement of community-based organs that the people respect and have confidence in, mismanagement of resources, lack of transparency, insufficient funds, lack of proper planning, non-mobilization of rural masses, government's insincerity of purpose, and lack of endurance and consistency in development plans, implementation and execution. "Many African countries, including Nigeria, have committed themselves to carrying out extensive economic reform programmes. The results have been somewhat mixed. In some cases a modest growth has been achieved through the transition from a centrally - planned economic system to a market based strategy. But in virtually all cases, the modest growth achieved has not translated into any significant improvement in poverty" (Aluko, 2003). "The programmes contributed minimally; they had little impact on the creation of additional jobs" Nwanna (2004).

\section{Theoretical Framework}

The theory underpinning this study is the macro theory extracted from the micro-macro perspective of poverty cited in Aluko (2003). According to macro perspective, poverty is seen as a social problem to be handled by systematic government action and provision of welfare services. Even if an individual desires a change in his position or status, institutionalised constraints within the socio-economic and political environment may hinder him from realizing this 
ambition. Some societies provide little possibility for upward social mobility to allow the poor to escape from their poverty. (Nobbs, 1984). In this sense, poverty is seen as a social problem, a macro political and economic issue that directs attention to the politics of poverty.

\section{Methodology}

Since the broad objective of this study is to assess the impact of government's intervention projects on poverty alleviation/reduction in Ekiti State, Nigeria, the researcher used survey design and judgmental sampling techniques to collect data from 630 respondents comprised of civil servants, farmers, and traders/artisans within the communities selected for the study, with the aid of a 25 -item structured questionnaire and personal interview. The questionnaire consisted of two sections, A and B. Section A was based on personal bio-data about the respondents while section B comprised of questions drawn from respondents to assess the impact of government's intervention projects on poverty alleviation/reduction in Ekiti State, Nigeria. Copies of the questionnaires were administered on a face-to-face basis, with the help of some youths in the communities under the supervision of their community leaders. The response rate was $83.1 \%$ meaning 648 were returned. However, 18 out of the 648 questionnaires returned were invalid, leaving the researcher with 630(80.77\%) questionnaires for analysis. Data for this study were analysed using descriptive statistics and chi-square $\left(X^{2}\right)$ was used to test the hypothesis posed for the research at $5 \%$ significant level.

\section{Research Questions}

The following are the research questions posed to guide the study.

1. What were the intervention projects/programmes executed in six Local Government Areas in the three Senatorial Districts in Ekiti State, Nigeria, selected for this study, from 2007-2011?

2. Who were the providers of these projects?

3. To what extent did the government's intervention projects impact on poverty alleviation of the people of Ekiti state from 2007-2011?

\section{Statement of Hypothesis}

- Ho: Provision of poverty alleviation/reduction projects/programmes did not have any impact on the people of the benefitting communities in Ekiti State from 2007-2011.

- H1: Provision of poverty alleviation/reduction projects/programmes had some impact on the people of the benefitting communities in Ekiti State from 2007-2011.

\section{Data Presentation and Analysis}

In order to answer the 3 research questions posed for this study, data generated from the field were analysed. The respondents' bio-data was first analysed for validity purposes. From the 25 -item structured questionnaire with open and closed ended questions, it was discovered that out of 780 copies of the questionnaire administered 648 copies were returned, 18 out of the 648 copies were invalid, leaving the researcher with 630 copies $(80.77 \%)$ for analysis. The response to question one, on the location of respondents, on the questionnaire revealed that the respondents were widely dispersed over the study area. $350(55.5 \%)$ of respondents were male, while the remaining $280(44.4 \%)$ were female. $140(22.3 \%)$ of the respondents were below 30 years of age, Majority of the respondents, $370(58.7 \%)$ had their ages between 30-50 years, and 120(19.0\%) were above 50 years. 180 (28.6\%) of the respondents had lived for more than 10 years in the communities selected for the study; 290 (46.0\%) had lived for 5-10 years while $160(25.4 \%)$ had lived in the communities below 5years. This means, a total of 470 respondents $(74.6 \%)$ had lived for 5years and above in the communities selected from each LGAs of the study. Therefore, the researcher believed that the respondent would have adequate knowledge about the required data/information on poverty alleviation/reduction projects/programmes in their various communities. $100(15.9 \%)$ of respondents were farmers, $380(60.3 \%)$ were traders/artisans, while the remaining $150(23.8 \%)$ were civil servants. 


\subsection{Results and Discussion of Findings}

The results of the study were presented in line with the objectives of the study.

Table 2: Answer to Research Question 1, Analysed with Question 10 on the Questionnaire. Poverty Alleviation Projects/Programmes executed in your community from 2007-2011 by various parties to Poverty Alleviation Projects/Programmes in your community, had some impact on the areas indicated below. Please kindly indicate the extent of your agreement with this statement by ticking the boxes provided beside the choices below.

\begin{tabular}{|c|l|c|c|c|c|c|c|c|c|}
\hline S/N & \multicolumn{1}{|c|}{ Projects/Interventions } & \multicolumn{2}{c|}{ Strongly Agree $\%$} & \multicolumn{3}{c|}{ Strongly Disagree $\%$} & \multicolumn{2}{|c|}{ Undecided \% } & \multicolumn{2}{c|}{ Total \% } \\
\hline 1. & Education/health services & 435 & 69 & 180 & 28.6 & 15 & 2.4 & 630 & 100 \\
\hline 2. & Micro Credit Scheme & 355 & 56.4 & 240 & 38.1 & 35 & 5.5 & 630 & 100 \\
\hline 3. & Construction/rehabilitation of rural roads/bridges & 386 & 61.3 & 208 & 33. & 36 & 5.7 & 630 & 100 \\
\hline 4. & Provision of water/electricity supply & 366 & 58.1 & 254 & 40.3 & 10 & 11.6 & 630 & 100 \\
\hline 5. & Women and Youth empowerment & 309 & 49.0 & 223 & 35.4 & 98 & 15.6 & 630 & 100 \\
\hline 6. & Good governance & 269 & 42.7 & 196 & 31.1 & 165 & 26.2 & 630 & 100 \\
\hline 7. & Small and medium scale industries & 185 & 29.4 & 424 & 67.3 & 21 & 3.3 & 630 & 100 \\
\hline
\end{tabular}

Table 2 shows the extent to which Poverty Alleviation Projects/Programmes executed in various areas by various parties to Poverty Alleviation Projects/Programmes, impacted on the areas indicated in the table from 2007-2011. In terms of Education/health services, $435(69 \%)$ of respondents strongly agreed with the statement, 180(28.6\%) strongly disagreed and 15(2.4\%) were undecided. On Microcredit Scheme, 355(56.4\%), 240(38.1\%), 35(5.5\%) of respondents strongly agreed, strongly disagreed and were undecided respectively, with the statement. On Construction of rural roads/bridges, $386(61.3 \%), 208(33 \%)$, and $36(5.7 \%)$ of respondents strongly agreed, strongly disagreed and were undecided respectively, with the statement. On the Provision of water/electricity supply, 366(58.1\%), 254(40.3\%), and 10(11.6\%) of respondents strongly agreed, strongly disagreed and were undecided respectively, with the statement. On Women and Youth empowerment, 309(49.0\%), 223(35.4\%), and 98(15.6\%) of respondents strongly agreed, strongly disagreed and were undecided respectively, with the statement. On Good governance, 269(42.7\%), 196(31.1\%), and 165(26.2\%) of respondents strongly agreed, strongly disagreed and were undecided respectively, with the statement. Also on Small and medium scale industries, 185(29.4\%), 424(67.3\%) and 21(3.3\%) of respondents strongly agreed, strongly disagreed and were undecided respectively, with the statement. This results therefore revealed that in Ekiti State, some of the Poverty Alleviation Projects/Programmes executed by various parties to Poverty Alleviation Projects/Programmes in the study area, had some impact on the various areas in which they were executed. However, the respondents strongly disagreed with the researcher's statement that Poverty Alleviation Projects/Programmes executed to alleviation poverty in respect of small and medium scale industries had some impact on alleviating/reducing poverty in Ekiti State, from 2007-2011.

Table 3: Answer to Research Question 2, Analysed with Question 17 on the Questionnaire. Which Donor Partners executed the largest number of poverty intervention projects/programmes in your community from 2007-2011?

\begin{tabular}{|c|l|c|c|}
\hline S/No & \multicolumn{1}{|c|}{ Donors } & No of Respondents & Percentages \\
\hline 1. & United Nations International Children's Emergency Fund (UNICEF) & 216 & $34.3 \%$ \\
\hline 2. & United Nations Development Program (UNDP) & 36 & $5.7 \%$ \\
\hline 3. & Department of International Development (DFID) & 72 & $11.4 \%$ \\
\hline 4. & WORLD BANK & 252 & $40.0 \%$ \\
\hline 5. & World Health Organization (WHO) & 10 & $1.6 \%$ \\
\hline 6. & United Nations International Development Organization (UNIDO) & 5 & $0.8 \%$ \\
\hline 7. & No Response & 39 & $6.2 \%$ \\
\hline \multicolumn{2}{|c|}{ Total } & 630 & $100 \%$ \\
\hline \multicolumn{2}{|c|}{} \\
\hline \multicolumn{2}{|c|}{}
\end{tabular}

Table 3 clearly shows that World Bank executed the largest number of poverty intervention projects/programmes in Ekiti State within the study period. 252(40\%) respondents attested to this. This may not be wrong as the researcher found out that the State is a beneficiary of Health System Development Programme (HSDP) and Community Based Poverty Reduction Programme by some Community Agencies in Ekiti State. (EKCPRA) which are World Bank Assisted Projects/Programme. 216(34.3\%) of respondents agreed that UNICEF had the largest number of intervention projects in 
the State. UNICEF is noted to have assisted the State in numerous projects/programmes related to women, children, and education. Also 72(11.4\%), 39(6.2\%), 36(5.7\%), 10(1.6\%), and 5(0.8\%) of respondents indicated DFID, No Response, UNDP, WHO, and UNIDO respectively.

Table 4: Answer to Research Question 2, Analysed with Question 22 on the Questionnaire. MDGs' poverty intervention projects were executed in your community from 2007-2011.

\begin{tabular}{|c|c|c|c|}
\hline S/No & Options & No of Respondents & Percentages \\
\hline 1. & YES & 480 & $76.2 \%$ \\
\hline 2. & NO & 80 & $12.7 \%$ \\
\hline 3. & No Response & 70 & $11.1 \%$ \\
\hline \multicolumn{2}{|c|}{ Total } & 630 & $100 \%$ \\
\hline
\end{tabular}

Table 4 shows that majority of the respondents 480(76.2\%) agreed that MDGs' poverty intervention projects were executed in their communities/Local Government Areas (LGAs) from the year 2007-2011. 80(12.7\%) did not agree with the statement, while $70(11.1 \%)$ of the respondents did not respond to the question. MDGs' projects in Ekiti State communities are focused on Education, Health Care services/facilities and provision of water. Personal interview with the respondents revealed that the MDGs' projects have helped their communities to a large extent in ameliorating their hardship in these areas.

Table 5: Answer to Research Question 3, Analysed with Questions 5-8 on the Questionnaire. The provision of poverty alleviation/reduction projects/programmes had some impact on the people of the benefitting communities in Ekiti State from 2007-2011, through the provision of: Education/health services (Q5), Micro Credit Scheme (Q6), Construction/rehabilitation of rural roads/bridges (Q7), and water/electricity supply (Q8). Please kindly indicate the extent of your agreement with this statement by ticking the boxes provided beside the choices below.

Observed Frequencies

\begin{tabular}{|c|c|c|c|c|c|}
\hline Response & Q5 & Q6 & Q7 & Q8 & Total \\
\hline SA & 502 & 509 & 537 & 397 & 1945 \\
\hline SD & 102 & 96 & 65 & 198 & 461 \\
\hline UN & 26 & 25 & 28 & 35 & 114 \\
\hline Total & $\mathbf{6 3 0}$ & $\mathbf{6 3 0}$ & $\mathbf{6 3 0}$ & $\mathbf{6 3 0}$ & $\mathbf{2 5 2 0}$ \\
\hline
\end{tabular}

Table 6: Computation of the Chi-square Value

\begin{tabular}{|c|c|c|c|c|}
\hline $\mathbf{O}$ & $\mathbf{E}$ & $\mathbf{O}-\mathbf{E}$ & $(\mathbf{O}-\mathbf{E})^{2}$ & $\frac{\mathbf{( 0 - E}^{2}}{\mathbf{E}}$ \\
\hline 502 & 486.25 & 15.75 & 248.06 & 0.51 \\
\hline 509 & 486.25 & 22.75 & 517.56 & 1.06 \\
\hline 537 & 486.25 & 50.75 & 2575.56 & 5.30 \\
\hline 397 & 486.25 & -89.25 & 7965.56 & 16.38 \\
\hline 102 & 115.25 & -13.25 & 175.56 & 1.52 \\
\hline 96 & 115.25 & -19.25 & 370.56 & 3.22 \\
\hline 65 & 115.25 & -50.25 & 2525.06 & 21.91 \\
\hline 198 & 115.25 & 82.75 & 6847.56 & 59.41 \\
\hline 26 & 28.5 & -2.5 & 6.25 & 0.22 \\
\hline 25 & 28.5 & -3.5 & 12.25 & 0.43 \\
\hline 28 & 28.5 & -0.5 & 0.25 & 0.01 \\
\hline 35 & 28.5 & 6.5 & 42.25 & 1.48 \\
\hline $\boldsymbol{X}^{\mathbf{2}}$ & & & & 111.45 \\
\hline
\end{tabular}

Ho: Provision of poverty alleviation/reduction projects/intervention did not have any impact on the people of the benefitting communities in Ekiti State from 2007-2011. 


\subsection{Interpretation of Opinion of Respondents}

Majority of the respondents 502(79.1\%) strongly agreed that the Provision of Education and Health care services within their communities had some impact on poverty alleviation/reduction of the people in their communities from 2007-2011. 102(16.2\%) strongly disagreed and 26 (4.1\%) were undecided. On the provision of microcredit scheme, 509(80.8\%) respondents strongly agreed that it had some impact, 96(15.2\%) strongly disagreed while 25 respondents (4.0\%) were undecided. On the provision of Construction/rehabilitation of rural roads/bridges, 537 respondents (85.2\%) strongly agreed with the researcher's statement that construction /rehabilitation of rural roads/bridges had some impact on poverty alleviation in their communities, $65(10.3 \%)$ respondents, strongly disagreed while $28(4.5 \%)$ were undecided. On the provision of water/electricity, $397(63 \%)$ of respondents strongly agreed that the provision of water/electricity had some impact on poverty alleviation in their communities, 198(31.4\%) respondents strongly disagreed, while 35(5.6\%) of respondents were undecided.

At $5 \%(0.05)$ level of significance and 6 degree of freedom, the chi-square table figure for this study was 5.348 while the chi-square calculated value $\left(\mathrm{x}^{2}\right)$ was 111.45 . It can be seen that the chi-square calculated value is greater than the chi-square table figure. Therefore the NULL hypothesis $(\mathrm{Ho})$ which states: Provision of poverty alleviation/reduction projects/intervention did not have any impact on the people of the benefitting communities in Ekiti State from 2007-2011, was rejected and the alternative hypothesis $(\mathrm{H} 1)$ accepted. That means, the provision of poverty alleviation/reduction projects/intervention had some impact on the people of the benefitting communities in Ekiti State from 2007-2011. However, personal interview with the respondents revealed that such impact was very little, insignificant, and has not led to the overall reduction or elimination of poverty of the people in the study area. This is not far from Aluko (2013)'s submission that "Many African countries, including Nigeria, have committed themselves to carrying out extensive economic reform programmes. The results have been somewhat mixed. In some cases a modest growth has been achieved through the transition from a centrally - planned economic system to a market based strategy. But in virtually all cases, the modest growth achieved has not translated into any significant improvement in poverty" (Aluko, 2003). Also, Nwanna (2004) confirmed that "The programmes contributed minimally".

\section{Conclusion}

This study examined the impact of government intervention projects on Poverty alleviation/ reduction in Ekiti State from 2007-2011. The study revealed that some poverty alleviation/reduction projects/programmes such as education/health services, provision of water, electricity supply, construction/rehabilitation of rural roads/bridges and provision of microcredit to farmers/traders/artisans, had some impact on the lives of the people especially those in the different communities/LGAs of study area. Personal interview with the respondents revealed that such impact was very insignificant and has not led to the overall poverty alleviation/reduction of the inhabitants in the study area. Also that World Bank and UNICEF are the two major donor agencies that have the largest number of poverty intervention projects/programmes in the State.

It is important for the Federal and Ekiti State government to implement a well-planned and concerted policy framework, projects/programmes, and provide an adequate budget, towards poverty alleviation/reduction, in Ekiti State. Also Ekiti State government should ensure that the efforts of all donor agencies and every party to the poverty alleviation/reduction projects/programmes in Ekiti State are properly coordinated so that their poverty intervention efforts would not be duplicated rather, they should complement each other. This is to avoid wasted efforts. Poverty alleviation/reduction projects/programmes should be fairly distributed in all communities and LGAs of the State and involvement of the community members in the conceptualization, and implementation of projects in order to identify the exact projects required to raise the standard of living and alleviate the lives of the people of Ekiti State is necessary.

\section{Appreciation}

We hereby appreciate Mr Otewogbola Festus Adegbola, for his immerse contribution to this study.

\section{References}

Aboyade, O. (1975) "On the Need for Operational Specification of Poverty in Nigeria "In Proceedings of 1975 Annual Conference of the Nigeria Economic Society. Ibadan; pp. 21- 27.

Aluko, M. A. O. (2003). Strategies for Poverty Reduction in Nigeria. Kamla-Raj 2003 J. Soc. Sci., 7(4): 255, 259. 
Elumilade, D.O., Asaolu, T. O. and Adereti, S. A. (2006). "Appraising the Institutional Framework for Poverty Alleviation Programmes in Nigeria". International Journal of Finance and Economics Vol. 3. Lagos pp $66-77$

Fashola, M. A. (2004). A Schema for Nigeria's Optimal Industrial Development. In Industrialization, urbanization and Development in Nigeria 1950-1999. Edited by M. O. A. Adejugbe. Lagos-Nigeria: Concept Publications Limited. PP. 307-311.

ljaiya, G. T. (1998). Alleviating Poverty in Nigeria: Investing in Education as a Necessary ecipe Ilorin journal of Education, 18, pp.125131.

Ishola, W. A. (2004). Sructural Adjustment and De-industrialization in Nigeria: 1986-1999. In Industrialization, urbanization and Development in Nigeria 1950-1999. Edited by M. O. A. Adejugbe. Lagos-Nigeria: Concept Publications Limited. PP. 356.

Kadiri, W. A. (1998). Reflections on Nigerian Urban Planning Issues. Abeokuta, Ogun State: DESI-OGA Publications. pp. 82, 95.

Nobbs, J. (1984). Sociology in Context London: Macmillan Education. In M. A. O. Aluko (2003). Strategies for Poverty Reduction in Nigeria. Kamla-Raj 2003 J. Soc. Sci., 7(4): p.259.

Nwabueze, N. (2004). Problems of Mobilizing Civil Society in Nigeria. In Industrialization, urbanization and Development in Nigeria 1950-1999. Edited by M. O. A. Adejugbe. Lagos-Nigeria: Concept Publications Limited. PP 136-139.

Nwakeze, N. M. (2004). Rural-Urban Growth Differentials in Nigeria, 1950-1990: A Divergence or convergence? In Industrialization, urbanization and Development in Nigeria 1950-1999. Edited by M. O. A. Adejugbe. Lagos-Nigeria: Concept Publications Limited. PP 103-107.

Nwanna, C. (2004). Rural-Urban Migration and Population Problems in Nigeria cities. In industrialization, urbanization and development in Nigeria 1950-1999. Edited by M.O.A. Adejugbe. Concept Publications Limited. pp. 66-69.

Obayelu, A. E. (2005) "Economics of Poverty, Environmental and Natural Resources Use: Implications and Remedies. Using Nigeria as Case Study" Retrieved from www. Obayelu.pdf. pp 32 - 38

Ogwumike, F.O. (2002) "An appraisal of Poverty and Poverty Reduction Strategies in Nigeria" CBN Economic and Financial Review Vol. 39 No. 4 Lagos; pp $21-35$

Olatunji, R. W. (2008). Towards achieving the MDGs in Nigeria. What Roles for cooperate Social Responsibility? In: E. M. Mojaye, O. O. Oyewo. R. M. Bayo, I. A. Sobowale (Eds): Globalization and Development Communication in Africa. Ibadan: University Press. P. 224.

Olise (2010). Information and Communication Technologies (ICTs) and Sustainable Development in Africa: Mainstreaming the Millennium Development Goals (MDGS) into Nigeria's Development Agenda. In J Soc Sci, 24 (3). Kamla-Raj. pp.156, $159,160$.

Olujimi, J. B. (2001). "Sustainable Development of Rural Infrastructure in Nigeria: An approach to poverty alleviation". In international journal of economics and development issues. Volume 1, Number 1, 2001. PP. 148-152.

Sen, A. (1985). Commodities and Capabilities, North-Holland, Amsterdam, the Netherlands. In Lorenzo Giovanni Bellu, and Paolo Liberati (2005). Impacts of Policies on Poverty. On-Line Resource Materials for Policy Making. Food and Agriculture Organization (FAO) of the United Nations. p. 2.

Thirlwall, A.P. (2003). "Growth and Development. (7th Edition) Palgrave, Macmillan. NewYork; pp. 25-38.

World Bank (2001).World Development Report 2000/2001-Attacking Poverty. New York: Oxford University Press. In Chimobi Ucha (2010). Poverty in Nigeria: Some Dimensions and Contributing Factors. Global Majority E-Journal, Vol. 1, No. 1 (June 2010), p. 46.

World Bank Report (1996). "Nigeria, Poverty in the Midst of Plenty - The Challenge of Growth with Inclusion”. Washington D.C. p 147. 